\title{
TINDAKAN KEKERASAN GURU TERHADAP SISWA DALAM INTERAKSI BELAJAR MENGAJAR (STUDI KASUS DI SMAN SURABAYA)
}

\author{
Tamsil Muis \\ Jurusan Bimbingan dan Konseling, Fakultas Ilmu Pendidikan, Universitas Negeri Surabaya \\ E-mail: tamsilmuis@gmail.com
}

\begin{abstract}
Abstrak
Penelitian ini dilakukan untuk menghasilkan sebuah penjelasan teoritis tentang proses dan penyebab terjadinya tindakan kekerasan dengan menekankan pada dinamika interaksi belajar mengajar antara pelaku (guru) dan korban (siswa). Dengan menggunakan metode penelitian kualitatif dalam bentuk studi kasus, proses penelitian diawali dengan menggali informasi dari pejabat Diknas kota Surabaya (Pengawas Sekolah), penentuan sekolah terjadinya kekerasan di sekolah menurut rekomendasi Waslah kota Surabaya, penentuan guru-guru yang pernah melakukan kekerasan melalui angket dari siswa, kemudian wawancara dan observasi terhadap guru-guru yang sering melakukan kekerasan dalam proses belajar mengajar. Hasil analisis data penelitian ini menunjukkan bahwa: (1) Diknas Surabaya belum memiliki suatu sistem monitoring/pemantauan tentang kekerasan dalam interaksi belajar mengajar (kibem) di sekolah; (2) Guruguru yang melakukan kibem, lebih disebabkan oleh paradigma dan wawasan kependidikannya, bahwa untuk menegakkan disiplin harus dengan kekerasan; (3) Hasil penelitian menunjukkan bentuk kekerasan yang sering terjadi di sekolah adalah kekerasan verbal (mengucapkan kata-kata kasar dan menyinggung perasaan), psikologis (mengabaikan, mengancam), dan fisik (menjewer, menendang, mencubit); (4) Siswa yang menjadi korban kekerasan menganggapnya sebagai sesuatu yang memang harus terjadi dan cenderung pasrah, hanya sebagian kecil siswa $(10,6 \%)$ yang mengakibatkan rasa dendam dalam diri mereka
\end{abstract}

Kata Kunci: kekerasan guru, interaksi belajar mengajar

\section{Abstract}

The purpose of this research is to get description about reason and happening process of violence in teaching learning process between teacher as subject and student as victim. Method of this research is qualitative research with case study design. Begin finding information from Department of National Education Surabaya, especially from the supervisor of school (usually called Pengawas Sekolah), this research corned in interview process with the teacher who known as a subject. The result of this research is (1) Department of National Education Surabaya haven't monitoring system which concentrated in violence action in teaching learning process, (2) the cause of violence action is focused on paradigm and knowledge of the teacher that to built student's discipline attitude is with violence action, (3) The kind of violence which happen in teaching learning process is verbal violence, physic violence, dan psychology violence, and (4) the victim of this violence action just can defensiveness and 10\% getting resentment.

Keywords: teacher violence, interaction of teaching and learning

\section{PENDAHULUAN}

Di Indonesia angka kekerasan terhadap anak secara umum semakin meningkat. Lembaga Perlindungan Anak (LPA) di Jawa Tengah melaporkan sepanjang JanuariNopember 2003 terdapat 285 kasus kekerasan dan eksploitasi atas anak, seorang diantaranya meninggal.

Sementara kasus kekerasan di sekolah juga telah banyak diliput media massa. Di Bengkalis, Riau, seorang guru SD Lubuk Gaung menghukum muridnya dengan hukuman berlari keliling lapangan dalam kondisi telanjang bulat (Jawa Pos, 25 April 2002). Bulan Maret 2002, seorang pembina pramuka bertindak asusila terhadap siswinya saat acara camping (Jawa Pos, 27 April 2002). Di Yogyakarta, pada 22 April 2002, ketika diadakan peringatan Hari Kartini di salah satu SMUN, seorang siswi, karena tidak berbusana "kartinian", ditelanjangi di hadapan rekan-rekannya hingga siswi tersebut tinggal mengenakan celana dalamnya (Jawa Pos, 22 April 2002). Media Indonesia (28 Nopember 2006), memberitakan bahwa di Goa - Sulawesi Selatan ada seorang siswa SMA meninggal akibat lemparan batu yang mengenai kepalanya oleh seorang guru olahraga.

Beberapa hipotesis bisa diajukan untuk menjelaskan fenomena kekerasan yang terjadi dalam dunia pendidikan. Pertama, kekerasan dalam pendidikan bisa muncul sebagai akibat adanya pelanggaran yang disertai dengan hukuman, terutama fisik. Kedua, kekerasan dalam pendidikan bisa diakibatkan oleh buruknya sistem dan kebijakan pendidikan yang berlaku. Ketiga, kekerasan 
dalam pendidikan mungkin pula dipengaruhi oleh lingkungan masyarakat dan tayangan media massa. Keempat, kekerasan bisa jadi merupakan refleksi dan perkembangan kehidupan masyarakat yang mengalami pergeseran cepat, sehingga meniscayakan timbulnya sikap instant solution dan jalan pintas. Dan, kelima, kekerasan mungkin pula dipengaruhi oleh latar belakang sosial-ekonomi pelaku.

Kekerasan dalam pendidikan merupakan perilaku melampaui batas kode etik dan aturan dalam pendidikan, baik dalam bentuk fisik maupun pelecehan atas hak seseorang. Pelakunya bisa siapa saja: pimpinan sekolah, guru, staf, murid, orang tua atau wali murid, bahkan masyarakat.

Berdasarkan latar belakang di atas, permasalahan yang diangkat dalam penelitian ini dirumuskan sebagai berikut: "mengapa dan bagaimana guru melakukan tindakan kekerasan dalam interaksi belajar-mengajar (kibem) terhadap siswa?" Selanjutnya permasalahan utama tersebut dapat dirinci sebagai berikut: 1) Bagaimana fenomena perilaku kibem guru terhadap siswa, 2) Kondisi-kondisi apa yang menjadi pemicu munculnya kibem, 3) Bagaimana guru memaknai perilaku kibemnya terhadap siswa, 4) Apa dampak kibem bagi siswa.

\section{Kajian Pustaka}

Ada tiga teori psikologis yang berbeda tentang penyebab kekerasan manusia, yaitu bersifat instinktif, semata-mata hasil belajar, dan respons innate yang didorong oleh frustrasi (Gilligan, 1996). Teori instink tentang kekerasan, diantaranya ditulis Freud (1953) tentang dorongan bagi tindakan destruktif terhadap instink yang mati dan tulisan Lorenz (1971) tentang agresi sebagai instink yang meningkatkan ketahanan hidup, mengasumsikan bahwa manusia memiliki sumber dorongan agresif yang sifatnya otonomi dari dalam dirinya, suatu dorongan untuk melakukan kekerasan yang dalam kata-kata Lorenz menunjukkan ledakan tak tertahankan yang muncul tertaur secara ritmis" (Lorenz, 1971).

Teori yang berlawanan menyatakan bahwa perilaku kekerasan semata atau terutama dipelajari menjadi ciri karya beberapa psikolog sosial dan psikolog anak. Mereka meyakini bahwa beberapa perilaku kekerasan diperoleh karena proses belajar dan digunakan secara strategis untuk tujuan tertentu. Teori ini banyak terdapat di beberapa pendekatan teoritis kontemporer tentang konflik kolektif diantara para pakar teori revolusi.

Teori psikologis ketiga adalah bahwa kebanyakan kekerasan terjadi sebagai respons terhadap frustrasi. Frustrasi merupakan gangguan dengan perilaku yang diarahkan oleh tujuan. Disposisi untuk memberikan respons agresif bila frustrasi adalah bagian ciri biologis manusia; ada kecenderungan inheren biologis, dalam manusia dan hewan, untuk menyerang pihak yang menyebabkan frustrasi. Rumusan teori frustrasi-agresi yang paling berpengaruh dikemukakan Dollard dan koleganya di Yale pada 1939 (Dollard \& Miller, 1950). Dalil dasarnya adalah "bahwa terjadinya perilaku kekerasan selalu mensyaratkan keberadaan frustrasi dan, sebaliknya, bahwa keberadaan frustrasi selalu menimbulkan beberapa bentuk kekerasan".

Singkatnya, sumber utama kapasitas manusia bagi kekerasan tampaknya adalah mekanisme frustrasi-agresi. Frustrasi tidak perlu menimbulkan kekerasan, dan kekerasan bagi orang-orang tertentu bisa dimotivasi oleh ekspektasi atau pencapaian tertentu. Namun, kemarahan yang disebabkan oleh frustrasi merupakan kekuatan pemotivasi yang mendorong manusia melakukan kekerasan.

Ketiga teori psikologis di atas terlalu menekankan penyebab kekerasan pada pelakunya. Karena itu belum dapat menjelaskan secara teoritis menyangkut interaksi yang terjalin antara pelaku dan korbannya dalam sebuah peristiwa kekerasan. Padahal setiap peristiwa kekerasan selalu melibatkan pelaku dan korbannya. Jenis interaksi tertentu yang berlangsung antara pelaku dan korban dalam sebuah tindakan kekerasan karena itu tidak bisa diabaikan begitu saja. Penelitian ini ingin mengungkap proses terjadinya tindakan kekerasan dan penyebabnya dengan menekankan pada dinamika interaksi antara pelaku dan korban.

\section{Definisi Operasional}

Kekerasan dalam interaksi belajar-mengajar (kibem) guru terhadap siswa didefinisikan sebagai sikap agresi guru yang melebihi kapasitas kewenangannya dan menimbulkan pelanggaran hak bagi si korban (siswa). Ditinjau dari tingkatannya, perilaku kekerasan dapat dibedakan menjadi tiga kelompok. Pertama, kekerasan tingkat ringan (soft violence) yakni berupa potensi kekerasan (violence as potential), umumnya berupa kekerasan tertutup (covert), pelecehan martabat dan penekanan psikis. Kedua, kekerasan tingkat sedang, yang berupa perilaku kekerasan terbuka (overt) yang terkait dengan penekanan fisik. Sedang tingkatan ketiga, adalah kekerasan tingkat berat, yakni tindak kriminal (criminal action), berbentuk kekerasan ofensif, penganiayaan (abuse), ditangani oleh pihak yang berwajib, ditempuh melalui jalur hukum, dan berada di luar wewenang pihak sekolah.

Penelitian ini berfokus pada pengertian kekerasan pada tingkat ringan (soft violence) dan tingkat sedang. Indikatornya mencakup: (a) Pelecehan martabat, seperti mengeluarkan kata-kata: “Goblok!", “Picik!”, dan 
sejenisnya. (b) Penekanan psikis, seperti: tidak mempedulikan, melempar penghapus ke papan tulis dari belakang kelas, dan sejenisnya. (c) Mengancam, seperti kata-kata: "Awas kamu!, nilai pelajaran saya akan rendah untuk kamu!", dan sejenisnya; serta (d) Kekerasan fisik, seperti menjewer, mencubit, menampar, dan lain-lain.

\section{METODE}

Penelitian ini menggunakan rancangan studi kasus tunggal dan multi kasus, dengan menggunakan dua analisa, pattern-matching, dan explanation-building. Pattern-matching adalah teknik membandingkan pola dari data empiris dengan pola yang telah diprediksi berdasarkan teori. Pada tahap explanation-building, analisis data dari penelitian studi kasus dilakukan dengan cara membangun penjelasan terhadap "kasus" yang dicermati.

Penelitian ini dilakukan dengan menempuh langkahlangkah berikut: 1) Menjaring sekolah-sekolah yang sering memiliki kasus kekerasan dalam interaksi belajar mengajar (kibem) berdasarkan rekomendasi Waslah, 2) Menjaring guru-guru yang melakukan kekerasan dalam interaksi belajar mengajar melalui angket yang disebarkan kepada siswa, 3) Fenomena kibem diperoleh dari hasil wawancara dan observasi kepada guru yang bersangkutan, 4) Dampak kibem diperoleh dari siswa yang bersangkutan, dan wawancara kepada pihak yang terkait..

\section{HASIL DAN PEMBAHASAN}

Berdasarkan hasil wawancara dengan pengawas sekolah diperoleh data bahwa: a) tidak ada mekanisme khusus untuk meminimalisir kibem, b) sekolah yang berpotensi terjadinya kibem adalah sekolah pinggiran yang cenderung kurang disoroti masyarakat, c) Istilah kibem masih sangat sensitif bagi pihak sekolah, perlu istilah lain, misal "Dampak Psikologis PBM terhadap siswa", d) pelaku kibem cenderung guru "senior" yang masih menganut paradigma lama bahwa "kekerasan adalah penegak disiplin", e) penyebab kibem antara lain : kepribadian guru, masalah personal, latar belakang budaya, f) terdapat perbedaan tindak kekerasan antara guru laki-laki dan perempuan.

Selanjutnya, berdasarkan rekomendasi Waslah, diperoleh lima sekolah di Surabaya yang akan diteliti : SMAN 2, SMAN 4, SMAN 15, SMAN 18 dan SMAN 16.

Angket siswa disebarkan untuk memperoleh data-data yang diinginkan. Berdasarkan hasil pengolahan angket siswa, diperoleh data sebagai berikut :

a. nama-nama pelaku tindak kekerasan, diperoleh 15 responden sebagai pelaku kekerasan dengan rincian : 4 responden dari SMAN 2, 4 responden dari SMAN
4, 2 responden dari SMAN 15, 3 responden dari SMAN 16, dan 2 responden dari SMAN 18.

b. jenis-jenis kibem yang sering muncul ; verbal (katakata dan julukan tidak menyenangkan), menyakiti fisik (menjewer, mencubit), dan psikologis (intimidasi/ancaman, melempar benda/barang)

Setelah menemukan nama-nama pelaku, maka ditindak lanjuti dengan wawancara. Hasil wawancara membuktikan bahwa semua responden mengakui tindakan yang telah dilakukan seperti berkata kasar, mencubit dan lain-lain, namun responden tidak merasa bahwa tindakan yang dilakukan adalah bentuk tindakan kekerasan. Responden beralasan bahwa apa yang dilakukan merupakan cara mendisiplinkan siswa dan membentuk mental siswa. Tindakan kekerasan di mata responden adalah tindakan yang tidak mendidik dan membuat siswa tidak nyaman. Selama dirasa perilaku yang diterapkan bertujuan untuk mendidik siswa maka tidak ada masalah dengan cara yang mereka gunakan.

Secara keseluruhan tentang bentuk tindak kekerasan yang dilaporkan oleh sampel sebanyak 200 orang responden, sejumlah 198 kejadian dengan rincian : kekerasan verbal sebanyak 60 (30.3\%) kejadian, kekerasan dengan memberikan label kepada siswa sebanyak 12 (6.1\%) kejadian, kekerasan dengan mengacuhkan siswa sebanyak 36 (18.18\%) kejadian, kekerasan dengan menggunakan benda sebanyak 29 $(14.65 \%)$, kekerasan dengan mengintimidasi sebanyak 33 (16.67\%) kejadian dan kekerasan fisik sebanyak 28 (14.14\%) kejadian.

Berdasarkan penelitian, penyebab tindakan kekerasan guru terhadap siswa berdasarkan persepsi siswa adalah sebagai berikut : sebesar 19,17\% menjawab tidak jelas, sebanyak $47.95 \%$ menjawab akibat kesalahan sendiri, $23.28 \%$ menjawab karena tempramen guru, dan $9.6 \%$ menjawab lain-lain, seperti tidak hormat pada guru dan ramai di dalam kelas.

Tindakan kekerasan yang dilakukan guru terhadap siswa pada umumnya dipandang oleh guru pelaku sebagai bentuk hukuman yang wajar. Para guru pelaku beralasan bahwa siswa sekarang sulit diatur dan didisiplinkan sehingga tindakan kekerasan perlu dilakukan agar mereka jera. Dan para guru pelaku menganggap bahwa siswa tidak tersakiti oleh tindakannya dan akan merasakan manfaat dari perlakuan tersebut di masa yang akan datang.

Dampak kibem terhadap siswa beragam, yaitu minder sebanyak 5,6\% siswa, sakit hati sebesar $35,6 \%$ siswa, marah sebesar $21,2 \%$ siswa, sedih $10,2 \%$ siswa, balas dendam sebesar $10,6 \%$ siswa, dan lain-lain sebesar $16,6 \%$ siswa. 


\section{PENUTUP}

\section{Simpulan}

1. Fenomena perilaku kibem guru terhadap siswa

Kekerasan dalam interaksi belajar mengajar yang terjadi antara guru dan siswa terdiri dari kekerasan verbal, kekerasan dengan memberikan label kepada siswa, kekerasan dengan menggunakan benda, kekerasan dengan mengintimidasi siswa dan kekerasan fisik.

2. Kondisi-kondisi yang memicu munculnya Kibem.

Kondisi pemicu kekerasan yang berhasil diungkap dalam penelitian ini berasal dari dua faktor. Pertama, faktor internal guru berupa gaya mengajar, gaya berinteraksi dan model pendisiplinan yang dipilih. Selain itu ada unsur karakteristik pribadi seperti kecenderungan mudah marah dan emosi. Kedua, faktor eksternal berupa perilaku siswa yang sering diamati para guru pelaku adalah tidak memperhatikan saat guru sedang mendengarkan, tidak mengerjakan tugas atau pekerjaan rumah yang diberikan, ramai di dalam kelas atau pada saat pelajaraan berlangsung (celometan), tidak membawa buku atau peralatan tertentu, melakukan tindakan mengganggu siswa lain seperti menyembunyikan sepatu, tas atau barang lainnya. Pelanggaran terhadap tata tertib yang memicu kekerasan sebagai hukuman dari guru berbentuk rambut gondrong, rambut disemir, baju tidak dimasukkan, rok terlalu pendek pada siswa putrid, atribut seragam tidak lengkap atau tidak sesuai aturan (misalnya kaos kaki yang terlalu pendek), dan terlambat masuk kelas.

3. Bagaimana guru memaknai perilaku kibem-nya

Para guru cenderung menganggap apa yang mereka lakukan adalah benar dan pada akhirnya nanti bermanfaat bagi siswa meskipun saat ini siswa merasa sakit hati dan tidak terima. Dalam mengarahkan dan membimbing itu tindakan kekerasan diperlukan, apalagi jika melihat perubahan perilaku siswa sekarang dibanding dulu, terutama dalam hal sopan santun, baik terhadap guru maupun orang tua. Tindakan pendisiplinan yang keras dipandang para guru berhasil membuat siswa disiplin.

4. Dampak kibem terhadap siswa

Dampak kibem terhadap siswa beragam, yaitu minder sebanyak 5,6\% siswa, sakit hati sebesar 35,6\% siswa, marah sebesar $21,2 \%$ siswa, sedih $10,2 \%$ siswa, balas dendam sebesar 10,6\% siswa, dan lain-lain sebesar $16,6 \%$ siswa.

\section{Saran}

Dinas Pendidikan Kota Surabaya belum memiliki suatu sistem monitoring atau pemantauan tentang kibem (kekerasan dalam proses belajar mengajar) di sekolah. Peneliti menyarankan agar sistem monitoring yang dilakukan Pengawas Sekolah dapat menjangkau kasus- kasus kibem di sekolah. Pengawas Sekolah perlu mempertimbangkan untuk memberikan pengarahan berkala kepada guru atau kepala sekolah berkenaan dengan peningkatan kinerja, atau pelatihan berkenaan dengan pengembangan metode mengajar yang kreatif dan tanpa kekerasan, untuk mengoptimalkan proses belajar mengajar di kelas.

Guru hendaknya menyadari bahwa kedisiplinan tidak identik dengan kekerasaan. Kedisiplinan memerlukan ketegasan, bukan kekerasan. Guru perlu pula mengembangkan diri melalui berbagai seminar atau pelatihan agar para guru memiliki cakrawala baru dan meninggalkan paradigma lama yang mengidentikkan kedisiplinan dengan kekerasan.

Bagi penelitian selanjutnya, perlu dilakukan penelitian lebih lanjut tentang faktor-faktor yang mempengaruhi munculnya kekerasan di dalam proses belajar mengajar yang akan memperkaya kajian penelitian ini. Penelitian lanjutan dengan populasi, serta setting yang lebih luas dapat memperkaya temuan penelitian ini. Penelitian di sekolah-sekolah swasta, pinggiran, atau sekolah-sekolah dengan karakteristik khusus lain, dapat memberikan kontribusi dalam tema ini.

\section{DAFTAR PUSTAKA}

Berkowitz, L. 2003. Emotional Behavior. Mc. Graw-Hill Inc.

Bogdan, R.C. \& Biklen, S.K. 1998. Qualitative Researh for Education: An Introduction to Theory and Methods. Boston: Allyn \& Bacon, Inc.

Bogdan, R.C. \& Taylor, S.T. 1975. Introduction to Qualitative Research Methods: A Phenomenological Approach to The Social Sciences. New York: John Wiley \& Sons.

Covey, S. 1998. The 7 Habits of Highly Effective Teens. New York: A Fireseide Book.

Creswell, J.W. 1994. Research Design: Qualitative \& Quantitative Approaches. London: Sage Publications Ltd.

Denzin, N.R. \& Lincoln, Y.S. 1994. Handbook of Qualitative Research. Thousand Ducks, California: Sage Publications, Inc.

Dollard, J. \& Miller, N.E. 1950. Personality and Psychotherapy. New York: Mc.Graw-Hill.

Flaherty, D.J. 2001. School Violence: Risk, Preventive Intervention and policy (Urban Diversity, series 109). Cleveland, OH: Case Western University.

Freud, S. 1953. Collected Papers. Vol. 1-5. Ed. E.Jones. London: Hogarth Press.

Gilligan, J. 1996. Violence as Tragedy. New York: Vintage Books. 
Jessor, R.J., Van Den Bos, J., Vanderryn, J., Costa, F.M., \& Turbin, M.S. 1995. Protective Factors In Adolescent Problem Behavior: Moderator Effects And Developmental Change. Developmental Psycology, 31. 923-933.

Johnson, David. 1998. "The Determinants of Deadly Force: A Structural Analysis of Police Violence". American Journal of Sociology. Volume 103, Number 4: 211-217.

Joni, R.T. 1983. Cara Belajar Siswa Aktif, Wawasan Kependidikan dan Pembaharuan Pendidikan Guru. Pidato pengukuhan pada peresmian penerimaan jabatan guru besar FIP IKIP Malang.

Joni, R.T. 2000. Memicu Perbaikan Pendidikan Melalui Kurikulum. Basis. No. 07-08 tahun ke-49, JuliAgustus 2000. Yogyakarta: Kanisius Halaman 4148.

Knowles, R.T., \& McLean, G.F. 1992. Psychological Foundations of Moral Education And Character Development: An Integrated Theory of Moral Development. Second Edition. Washington: The Council For Research In Values And Philosophy.

Kompas, 27 Juli 2005.

Lincoln. Y.S. \& Guba, E.G.L. 1985. Naturalistic Inquiry. Berverly Hill, CA: Sage Publications, Inc.

Lorenz, K. 1971. Studies in Animal and Human Behavior. Cambridge, Mass: Harvard University Press.

Lorenz. 1963. On Agression. New York: Harcourt.

Marshall, C. \& Rosman, G.B. 1989. Designing Qualitative Research. Newbury Park. California: Sage Publications.

Media Indonesia, 28 Nopember 2006.

Moleong. L.J. 1989. Metodelogi Penelitian Kualitatif. Bandung: Remaja Karya.

Newman, W.L. 2000. Social Research Methods: Qualitative \& Quantitative Approaches. Fourth Edition. Boston: Allyn and Bacon.

Smith. J.M. \& Lusterman, D.D. 1979. The Teacher As Learning Fasilitator: Psychology and The Educational Process. California: Wadsworth Publishing Company, Inc.

Strauss A., \& Corbin, J. 1990. Basics Of Qualitative Research: Grounded Theory Procedurs and Techniques. London: Sage Publications Ltd.

Yin, R. 1996. Case Study Research: Design and Methods. London: Sage Publications Ltd. 